\title{
Radical Cystectomy for Bladder Cancer in the 70+ Population: A Nation-Wide Registry Analysis of 845 Patients
}

\author{
Stephan Madersbacher ${ }^{\mathrm{a}} \quad$ Wilhelm Bauer $^{\mathrm{b}}$ Manfred Willinger ${ }^{\mathrm{c}}$ \\ Clemens Wehrberger $^{\mathrm{a}}$ Ingrid Berger ${ }^{\mathrm{a}} \quad$ Clemens Brössner $^{\mathrm{b}}$ \\ a Department of Urology and Andrology, Danube Hospital, ' Department of Urology, Göttlicher Heiland Hospital, \\ and ${ }^{\mathrm{C}}$ Austrian Health Institute, Vienna, Austria
}

\section{Key Words}

Radical cystectomy $\cdot$ Elderly $\cdot$ Nation-wide data

\begin{abstract}
Aim: To analyze demographics, perioperative mortality and overall survival of radical cystectomy $(R C)$ in patients aged $70+$ years in Austria in a nation-wide registry cohort. $\mathbf{P a}$ tients and Methods: All patients $>69$ years who underwent $\mathrm{RC}$ in public hospitals (covering $>95 \%$ of all surgical procedures) in Austria between 1992 and 2004 were analyzed. Data were provided by the Austrian Health Institute (ÖBIG). Results: A total of 845 patients aged $70-89$ years (mean 74 ) entered the analysis. The annual number of cystectomies in this age group increased from 27 in 1992 to 79 (+292\%) in 2004. The mean length of hospital stay declined from 37.1 days (in 1992) to 27.1 days (in 2004). The 60-day mortality of the entire cohort was $1.5 \%$ and increased to $5.2 \%$ in patients aged $80+$ years. Almost $50 \%$ of patients had to be rehospitalized within 30 days. The 5 -year overall survival declined from $62 \%$ in those aged $70-74$ years to $61 \%$ in those aged $75-79$ years to $46 \%$ in the oldest age group ( $80+$ years). Conclusions: The annual number of cystectomies in patients aged $70+$ years increased substantially during the study period.
\end{abstract}

These nation-wide registry data provide insights into the current status of RC in the elderly in Austria and demonstrate that cystectomy in this age cohort can be done with an acceptable perioperative mortality and overall survival.

Copyright $\odot 2010$ S. Karger AG, Basel

\section{Introduction}

Bladder cancer is a tumor entity of the elderly with a peak incidence around 85 years of age [1-3]. Due to demographic changes with a threefold rise in the number of octogenarians in the next 25 years, there will be a steep increase of elderly patients with non-invasive but also with invasive bladder cancer [1-3]. The substantial morbidity but also mortality of invasive bladder cancer in the elderly paralleled with significant costs involved underlines the increasing relevance of this topic, also from the socioeconomic standpoint.

The optimal management of elderly patients with invasive bladder cancer is a controversial issue [4-6]. While pelvic lymphadenectomy and radical cystectomy (RC) is the accepted standard of care for younger patients with muscle-invasive bladder cancer, the role of cystectomy in

\section{KARGER}

Fax +4161306 1234 E-Mail karger@karger.ch www.karger.com
(C) 2010 S. Karger AG, Basel

0042-1138/10/0853-0287\$26.00/0

Accessible online at:

www.karger.com/uin
Stephan Madersbacher, MD, FEBU

Department of Urology, Donauspital

Langobardenstrasse 122, AT-1220 Vienna (Austria)

Tel. +43128802 3700, Fax +431288023780

E-Mail stephan.madersbacher@wienkav.at 


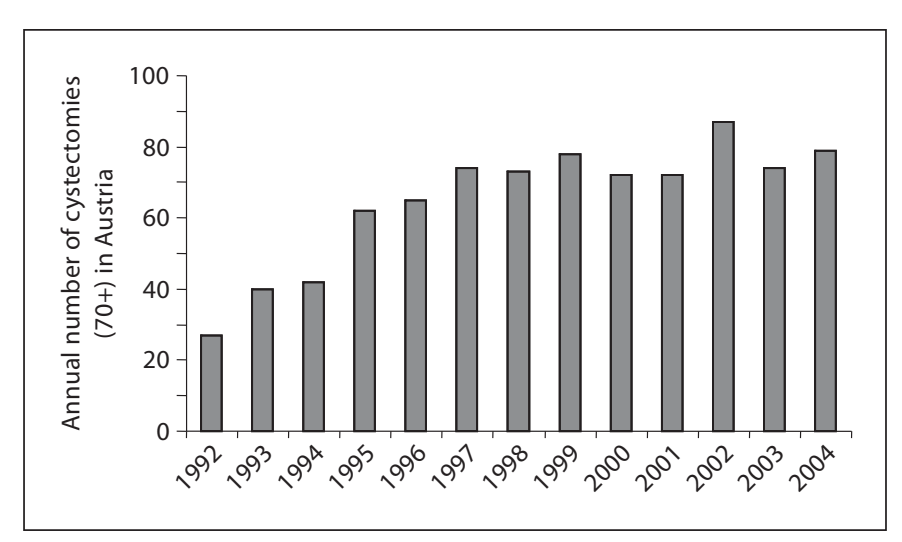

Fig. 1. Annual number of RCs in patients aged 70+ years in Austria from 1992 to 2004.

the elderly is less clearly defined [7-12]. A few cystectomy series - mostly published by centers of excellence - have documented the feasibility of this approach in the elderly, yet it remains unclear whether these data can be extrapolated to a broader basis [5].

For decades, Austria has had a public and equal access health system with compulsory insurance coverage. Nation-wide hospital data are centrally collected by the Austria Health Institute, therefore enabling a nation-wide registry analysis. For the current report we analyzed all patients $\geq 70$ years who were treated by RC for invasive bladder cancer in Austrian public hospitals (covering $>95 \%$ of all procedures) over a 12 -year period. With a total of 845 patients $\geq 70$ years, this is one of the largest series worldwide.

\section{Patients and Methods}

The Austrian Health Institute (ÖBIG) collects data of all patients admitted to public hospitals in Austria (covering $>95 \%$ of all surgical procedures). For the current analyses, all patients $\geq 70$ years who were admitted with the diagnosis of bladder cancer (ICD code: C67) and subsequently underwent RC were included. The analysis covered the time span of RC from 1.1.1992 to 31.12.2004. Data were censored by 1.1.2007.

The following data were extracted from the database: age at surgery, length of hospital stay, readmissions within 30 days, duration of readmissions, mortality within 60 days, overall and agestratified survival.

Kaplan-Meier curves were used to estimate overall survival in different age groups. The log-rank test was used to compare overall survival in different age groups, a p value $<0.05$ was considered statistically significant.

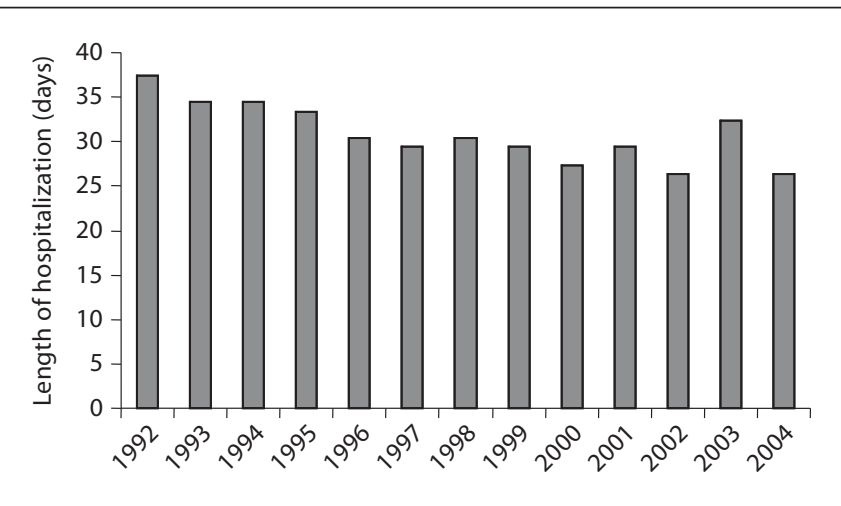

Fig. 2. Length of hospitalization in Austria from 1992 to 2004.

\section{Results}

\section{Patient Demographics}

A total of 845 patients $\geq 70$ years underwent RC between 1992 and 2004 in Austrian public hospitals. The annual number of cystectomies in the $70+$ population increased from 27 in 1992 to 79 in 2004 (+292\%) (fig. 1). The mean age of the entire cohort was $74 \pm 3.4$ ( \pm SEM) with a range of 70-89 years. The age distribution was as follows: $70-74$ years, $n=517 ; 75-79$ years, $n=269$, and $80+$ years, $n=59$. Mean age at surgery increased slightly from 73.7 years in 1992 to 74.9 years in 2004 .

\section{Hospitalization and Perioperative Mortality}

The length of hospitalization decreased from 37 days in 1992 to 26 days in 2004 (fig. 2). The rehospitalization rate within 30 days was $47 \%$ (396/845): in patients aged 70-74 years it was $47 \%$, in those age $75-79$ years $43 \%$, and in the oldest age group (80+ years) $58 \%$. The mean length of hospital stay during this rehospitalization was 7.5 days. The 60 -day mortality rate was $1.5 \%$ and increased from $0.5 \%$ (70-74 years) to $1.5 \%$ ( $75-80$ years) and $5.2 \%$ ( $>80$ years).

\section{Overall Survival}

A total of $320(37.9 \%)$ patients died during follow-up: 70-74 years: $37.5 \%$; $75-79$ years: $36.4 \%$, and $80+$ years: $47.5 \%$. As estimated by Kaplan-Meier analysis, the 1-, 3and 5 -year overall survival of the entire cohort was 88,68 , and $60 \%$, respectively (fig. 3). As expected, there was a clear age dependency of overall survival: the 5 -year overall survival declined from $61 \%$ (70-74 years) to $60 \%$ (7479 years) and $46 \%$ in those $\geq 80$ years (fig. 4 ). The 5 -year overall survival in the 70 - to 74 -year group was not dif- 


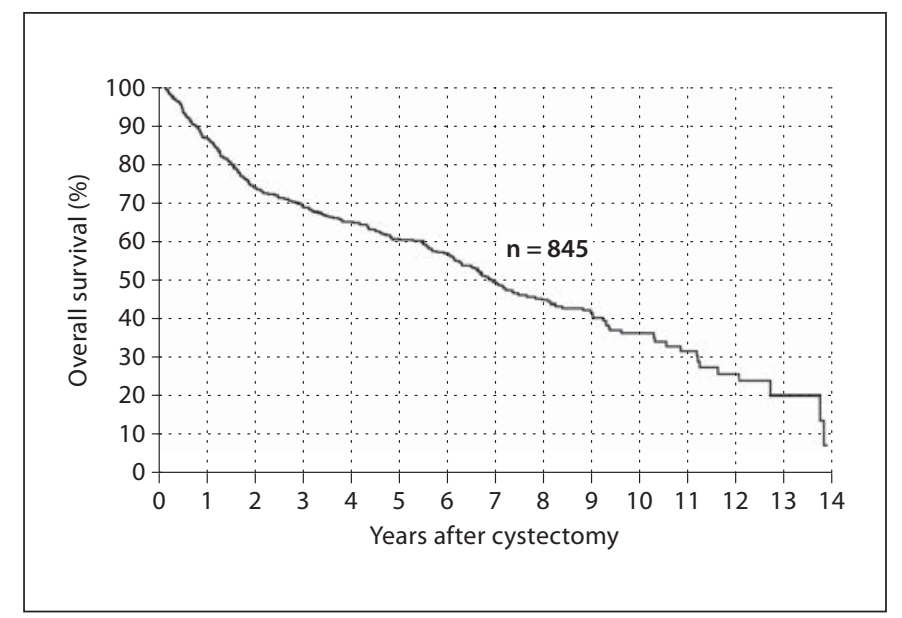

Fig. 3. Overall survival of the entire study cohort $(\mathrm{n}=845)$.

ferent to the 75 - to 80 -year group $(\mathrm{p}=0.22)$. However, the 70 - to 74-year group and the 75- to 80-year group had a significantly shorter overall survival than the $80+$-year group $(\mathrm{p}=0.01)$.

\section{Discussion}

The optimal management of elderly patients with invasive bladder cancer is a controversial issue $[4,9]$. Demographic changes will lead to a substantial increase of this particular group of patients, thus emphasizing the clinical relevance of this tumor entity. The relative paucity of clinical data on this topic was the rationale for the current study. Nation-wide data avoid the potentially induced bias of high-volume surgeons/centers and would therefore allow a more realistic assessment. For decades, Austria has had a public healthcare system with compulsory insurance, hence these data are not biased for example by income, social and insurance status. With over 800 patients aged $\geq 70$ years, this is one of the largest cystectomy series on this issue.

However, prior to discussion, several limitations of our study need to be considered: (i) histological data were not available to us; (ii) the analysis was limited to data entered into the ÖBIG database, hence information such as ASA score or Charlson score were not available; in addition, we had no information on the type of urinary diversion, pelvic lymphadenctomy, intra- and postoperative complication, etc.; (iii) due to Austrian law, we were not allowed to cut the data to individual centers, therefore we

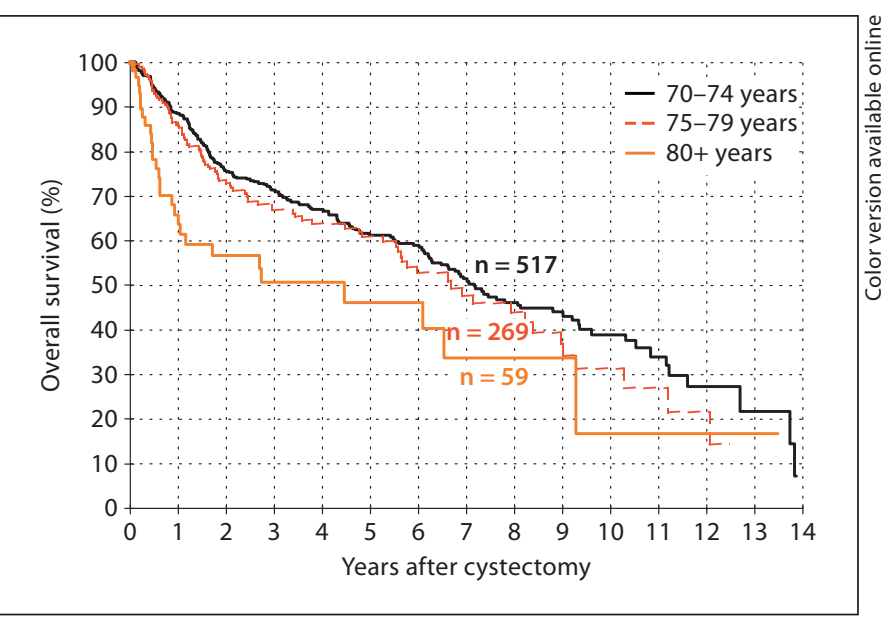

Fig. 4. Overall survival in different age groups.

were unable to assess the impact of surgical volume on morbidity and survival, and (iv) most importantly, the ÖBIG database contains only information of hospital admissions, hence if for example complications were managed on an outpatient basis, this information is lacking.

There are a few reports available documenting feasibility, oncological efficacy but also morbidity of cystectomy in the elderly. Froehner et al. [5] recently published an excellent review on morbidity and mortality of RC in the elderly. Perioperative mortality following cystectomy in patients aged $70+$ was reported in 19 studies, only three contained more than 100 patients [5, 13-15]. The perioperative mortality (30-90 days) in these 19 studies ranged from 0 to $11 \%$ [5]. However, several small-sized series reporting $0 \%$ mortality are difficult to interpret [5]. In series with more than 50 patients $(n=10)$ perioperative mortality ranged between 2 and 7.2\% [5]. Three series using a 90-day mortality definition reported on different perioperative mortality rates depending on defined age groups: $>65$ years of $5.5 \%,>75$ years of $7.5 \%$, and $>80$ years of $11 \%$ [15-17]. The 60-day mortality in our cohort $(\mathrm{n}=845)$ with a mean age of 74 years was $1.5 \%$ and increased with age from $0.5 \%$ (70-74 years) to $1.5 \%$ (75-80 years) and $5.2 \%$ ( $>80$ years). These nation-wide data fit well in the spectrum of previously published series [5].

The length of hospitalization during cystectomy was long (26 days in 2004) particularly in relation to US series. This is due to the fact that our healthcare system provides no incentive to dismiss patients early. The morbidity of $\mathrm{RC}$ in the elderly is substantial and well documented. The most frequent complications are ileus in up to $32 \%$, py- 
elonephritis in up to $40 \%$, and wound infection in more than $10 \%$ [5]. The ÖBIG database does not contain any detailed information regarding postoperative complications or reinterventions. The rehospitalization rate of our cohort however provides a rough idea on the morbidity involved: within 30 days, $47 \%(396 / 845)$ had to be rehospitalized. In the oldest age group (80+) almost two thirds of the patients had to be readmitted. The mean length during the rehospitalization was 7.8 days.

The overall survival of our cohort fits well to previously published series, and even slightly exceeds these series in the range of $10 \%$ [5]. This survival difference is most likely due to the fact that death rates only entered the ÖBIG database if the patient died in hospital. Due to Austrian law it is forbidden for the ÖBIG to give individual names to researchers. Therefore, it is not possible for us to track patients individually and to assess mortality rates outside hospital-based mortality.

The 3-year overall survival of the entire cohort was 70\% and at 5 years $60 \%$. In patients aged $70-74$ years the respective figures were 72 and 61\%, in those aged $75-79$ years 66 and $61 \%$, and in the oldest age group (80+) 50 and $46 \%$, respectively. Clark et al. [13] presented a large series of elderly $(70+)$ patients who underwent cystectomy $(n=364)$ : in the 70- to 79-year cohort, the 3- and 5-year overall survival was 64 and $54 \%$ and in the $80+$ cohort 51 and $46 \%$.

In contrast to younger patients, the oncological superiority of RC to bladder-sparing approaches in octoge- narians is not convincingly documented. By analyzing the Surveillance Epidemiology and End Result (SEER) database, Chamie et al. [8] investigated the outcome of patients treated either with RC or bladder-sparing procedures between 1992 and 2004. In contrast to younger age groups, the median overall survival for octogenarians ( $\geq 80$ years) was almost identical in the two treatment arms: 18 months for RC $(\mathrm{n}=904)$ versus 15 months for those who received bladder-sparing therapy $(n=1,227)$ [8]. We recently reviewed all patients $>80$ years with invasive bladder cancer ( $\geq \mathrm{pT} 1$ ) who underwent a bladdersparing approach at our institution [6]. According to this retrospective series, patients with $\mathrm{pT} 1$ tumors can be safely managed with a bladder-sparing approach; those with pT2 tumors and high comorbidity should also be managed conservatively because of the poor overall survival [6]. Those in good physical health and with muscle-invasive tumors should be offered RC [6].

In conclusion, these nation-wide registry data provide insights into the current status of RC in the elderly in Austria and demonstrate that cystectomy in this age cohort can be done with an acceptable perioperative mortality and overall survival. It is one of the largest series on this topic. The substantial morbidity and perioperative mortality of this approach in elderly suggests a risk-stratified approach taking tumor stage, chronological age, degree of comorbidity and projected life expectancy into consideration.

\section{References}

1 Ferlay J, Autier P, Boniol M, Heanue M, Colombet M, Boyle P: Estimates of the cancer incidence and mortality in Europe in 2006. Ann Oncol 2007;18:581-592.

2 Statistik Austria. Krebsinzidenz und Krebsmortalität in Österreich, www.statistik.at/ web_de/static/krebsinzidenz_und_krebsmortalitaet_in_oesterreich_2004_standardpublikation_024780.pdf, p 64.

3 Schultzel M, Saltzstein SL, Downs TM, Shimasaki S, Sanders C, Sadler GR: Late age ( 85 years or older) incidence of bladder cancer. J Urol 2008;179:1302-1306.

4 Shariat SF, Milowsky M, Droller MJ: Bladder cancer in the elderly. Urol Oncol 2009;27: 653-667.

5 Froehner M, Brausi MA, Herr HW, Muto G, Studer U: Complications following radical cystectomy for bladder cancer in the elderly. Eur Urol 2009;56:443-454.

-6 Wehrberger C, Berger I, Marszalek M, Ponholzer A, Wehrberger M, Rauchenwald M, Madersbacher S: Bladder preservation in octogenarians with invasive bladder cancer. Urology 2010;75:370-375.
7 Madersbacher S, Hochreiter W, Burkhard F, Thalmann GN, Danuser H, Markwalder R, Studer UE: Radical cystectomy for bladder cancer today - a homogeneous series without neoadjuvant therapy. J Clin Oncol 2003;21: 690-696.

$\checkmark 8$ Chamie K, Hu B, Devere White R, Ellison LM: Cystectomy in the elderly: does survival benefit in younger patients translate to the octogenarians? BJU Int 2008;102:284-290.

$\checkmark 9$ Lance RS, Grossman HB: Cystectomy in the elderly. Semin Urol Oncol 2001;19:51-55.

$\checkmark 10$ Buscarini M, Josephson DY, Stein JP: Lymphadenectomy in bladder cancer: a review. Urol Int 2007;79:191-199.

-11 Baltaci S, Resorlu B, Yagci C, Turkolmez K, Gogus C, Beduk Y: Computerized tomography for detecting perivesical infiltration and lymph node metastasis in invasive bladder carcinoma. Urol Int 2008;81:399-402.

12 Maurer T, Maurer J, Retz M, Paul R, Zantl N, Gschwend JE, Treiber U: Influence of body mass index on operability, morbidity and disease outcome following radical cystectomy. Urol Int 2009;82:432-439.
13 Clark PE, Stein JP, Groshen SG, Cai J, Miranda $G$, Lieskovsky $G$, Skinner DR: Radical cystectomy in the elderly: comparison of clinical outcomes between younger and older patients. Cancer 2005; 104:36-43.

14 Elting LS, Pettaway C, Bekele BN, Grossman HB, Cooksley C, Avritscher EB, Saldin K, Dinney CP: Correlation between annual volume of cystectomy, professional staffing, and outcomes: a state-wide, populationbased study. Cancer 2005; 104:975-984.

-15 Boström PJ, Kössi J, Laato M, Nurmi M: Risk factors for mortality and morbidity related to radical cystectomy. BJU Int 2009;103:191196.

16 Zebic N, Weinknecht S, Kroepfl D: Radical cystectomy in patients aged $>75$ years: an updated review of patients treated with curative and palliative intent. BJU Int 2005;95:12111214 .

17 Mendiola FP, Zorn KC, Gofrit ON, Mikhail AA, Orvieto MA, Msezane LP, Steinberg GD: Cystectomy in the ninth decade: operative results and long-term survival outcomes. Can J Urol 2007;14:3628-3634.
Madersbacher/Bauer/Willinger/ Wehrberger/Berger/Brössner 